\title{
Rupture of a presumed hydatid cyst of the interventricular septum diagnosed by transoesophageal echocardiography
}

\author{
I Sabah, F Yalcin, T Okay
}

Department of Cardiology, Acil Yardim Hospital, Balgat, Ankara, Turkey I Sabah

F Yalcin

\section{Cardiology}

Department, Bayindir Medical Center,

Balgat, Ankara, Turkey T Okay

Correspondence to: Dr Yalcin, Tomurcuk sok. 3/13 Aşaği Ayranci, Ankara 06540 Turkey.

Accepted for publication 29 October 1996

Figure 1 Transoesophageal echocardiography showing a hydatic cyst $(2.72 \times 3.54 \mathrm{~cm})$. graphy and confirmed by transoesophageal echocardiography.

\section{Case report}

A 33 year old woman presented to the emergency room with chest pain of sudden onset that had lasted six hours and became progressively intense with time; she was transferred to the cardiology clinic. In addition to chest pain, she complained of periodic palpitations and dyspnoea on exertion. Blood pressure was $90 / 40 \mathrm{~mm} \mathrm{Hg}$ and pulse rate 123 beats/ min. Cardiac auscultation revealed tachycardic first and second heart sounds. There was a grade 4/6 holosystolic and 3/6 decrescendo diastolic murmur, most prominent at the left sternal edge.

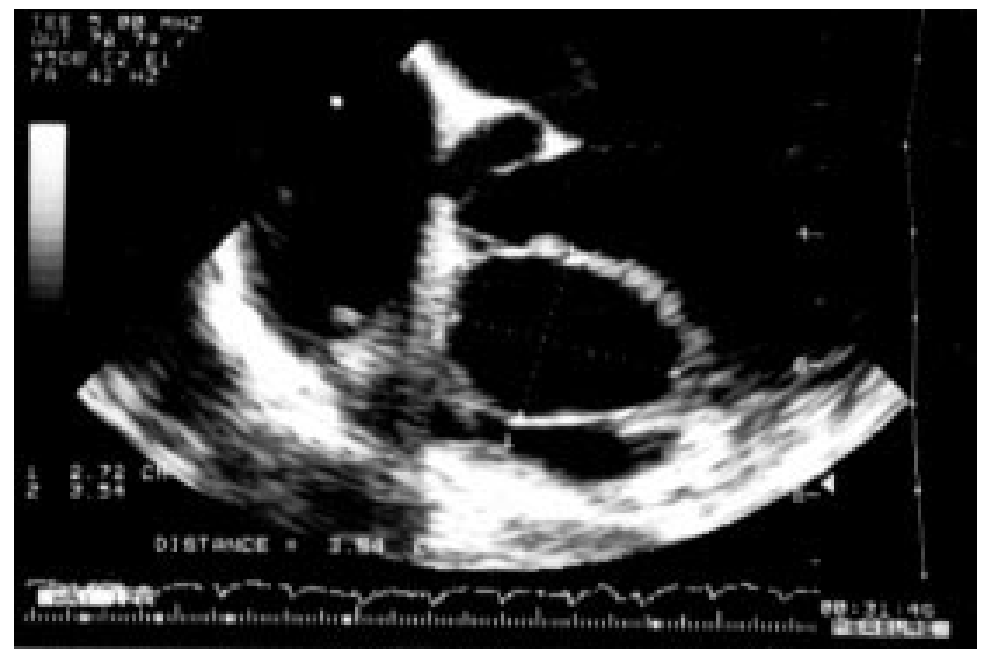

Cardiac echinococcosis is an infrequent disease and is seen in $0.2-3 \%$ of patients with echinococcal disease. ${ }^{1}$ Transthoracic echocardiography has been used to diagnose and evaluate intracardiac echinococcosis. ${ }^{12}$ Septal involvement of the hydatid cyst is observed quite rarely and is always associated with various conduction disturbances, as well as sudden death from arrhythmias. ${ }^{3}$ Cardiac involvement with echinococcosis may result in other potentially lethal complications. ${ }^{4}$ There have been many case reports of cardiac cysts; however, there have been none demonstrating a ruptured hydatid cyst by transthoracic echocardio-

\section{Discussion}

A cardiac cyst localised to the mediobasal portion of the interventricular septum seen with cross sectional echocardiography has been reported previously, ${ }^{2}$ and a cyst in the right atrium has been demonstrated using transoesophageal echocardiography. ${ }^{5}$ Cyst rupture is a common complication of cardiac echinococcosis, mostly in to the left ventricle, and is often lethal. ${ }^{6}$ Cardiac cysts can mimic various cardiac diseases even in the case of septal localisation, and often the first symptoms are related to cyst rupture. ${ }^{3}$

Although the present patient complained of dyspnoea and palpitations, she had not previously sought medical attention. The patient was in critical condition when she was admitted so a diagnostic evaluation was 


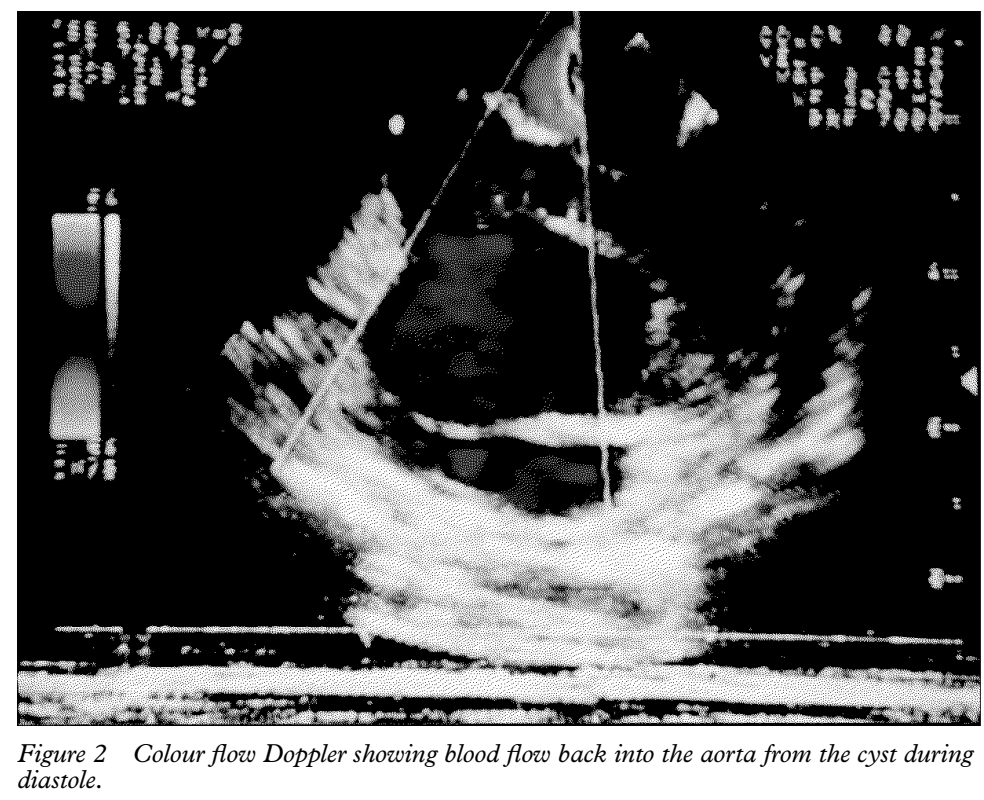
diastole.
This report describes the first documentation by transoesophageal echocardiography of a rare complication of a relatively common disease in developing countries. The ability to perform transthoracic echocardiography immediately will contribute to quick diagnosis in patients with ruptured hydatid cyst, especially in the differential diagnosis of the patients with chest pain. Transoesophageal echocardiography additionally shows details of any cyst rupture. The present patient's death was perhaps caused by low cardiac output related to the cyst rupture, limitation of anterior mitral valve excursion by the cyst mass, or possible anaphylactic reaction after the rupture.

Patients with hydatid cysts need to be evaluated and treated quickly to prevent sudden death, especially if rupture is documented. Despite adequate medical facilities, a serious problem in developing countries is that patients do not present until late in to the disease.

We thank Dr Richard Grimm (Cardiac Imaging Cleveland Clinic Foundation) for reviewing during manuscript preparation. This case was presented at the third international echocarUK in April 1996.

ings were in agreement with colour flow Doppler mapping.

Rupture is a lethal complication of hydatid cyst, especially if not acted on quickly following the initial symptoms, or if the patient presents late. Sudden death caused by various conduction disturbances is observed even in unruptured septal cysts leading to fatal arrhythmias. $^{3}{ }^{4}$ Di Bello and Menendez ${ }^{6}$ reported that intracardiac rupture occurred in 104 of 269 cases of cardiac echinococcosis; $88 \%$ in the right ventricle, and $37 \%$ in the left ventricle. In the same article, $29 \%$ of the cases with ruptured hydatid cyst were associated with sudden death. ${ }^{6}$
1 Bayezid O, Ocal A, Isik O, et al. A case of cardiac hydatid cyst localized on the interventricular septum and causing pulmonary emboli. F Cardiovasc Surg 1991;32:324-6.

2 Papagna D, Aloe MA, Spagnolo S. Cardiopulmonary echinococcosis: a report of a clinical case. G Ital Cardiol 1991;21:1129-33.

3 Gianmaria O, Massimo V, Ruggero DP, et al. Restoration of atrioventricular conduction after surgical removal of a hydatid cyst of the interventricular septum. I Thorac Cardiovasc Surg 1987;93:144-7.

4 Perez Gomez F, Duran H, Tamames S, et al. Cardiac echinococcosis: clinical picture and complications. $B r$

5 Ambrosi P, Mesana T, Habib G. Right intra-atrial extension of hydatid cyst mimicking cardiac thrombosis. Apropos of a case. Arch Mal Coeur Vais 1992;85:909-12.

6 Di Bello R, Menendez BS. Intracardiac rupture of hydatid cysts of the heart. Circulation 1963;27:366-74. 